\title{
THEORY OF SMOOTHNESS OF MOVEMENT OF MULTIPLE-AXLE Agricultural COMbined Tractor-IMPlement Units
}

\author{
Volodymyr Bulgakov, Volodymyr Kuvachov \& Jüri Olt
}
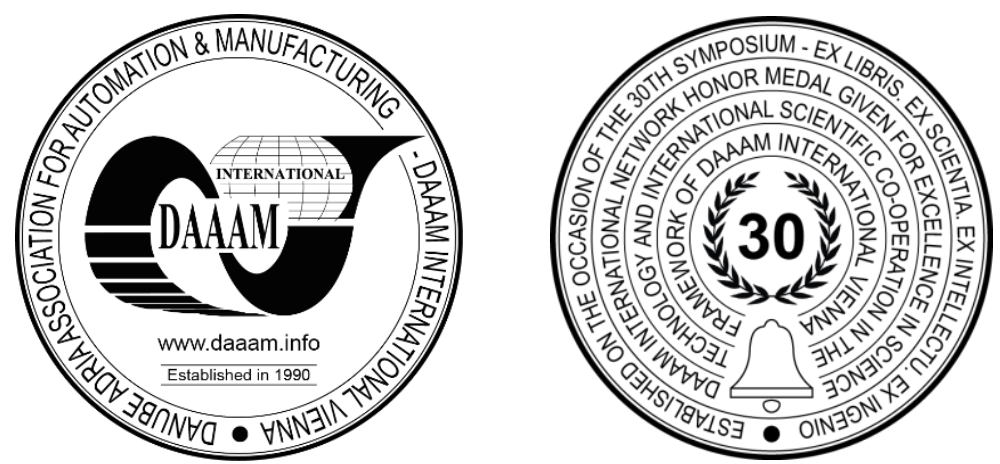

This Publication has to be referred as: Bulgakov, V[olodymyr]; Kuvachov, V[olodymyr] \& Olt, J[ueri] (2020). Theory of Smoothness of Movement of Multiple-Axle Agricultural Combined Tractor-Implement Units, Proceedings of the 31st DAAAM International Symposium, pp.0056-0065, B. Katalinic (Ed.), Published by DAAAM International, ISBN 9783-902734-29-7, ISSN 1726-9679, Vienna, Austria DOI: $10.2507 / 31$ st.daaam.proceedings.008

\begin{abstract}
The smoothness of movement of modular power units operated as parts of agricultural combined units, which are multiple-axle process systems, is a most important performance criterion. The research into the elastic damping properties of the process module of the modular power unit is of certain interest, because it could provide for a substantial reduction of the dynamic load on the transmission and engine of the power unit (module). The aim of the research is to improve the smoothness of movement of the modular power unit as part of an agricultural combined unit by means of developing an elastic damping link between the power module and the process module. The research resulted in finding new patterns of the impact that the parameters of the elastic and dissipative link between the two modules had on the characteristics of the vertical oscillations of the modular power unit. It was proved that by applying the rational rigidity of the elastic and dissipative link between the two modules it was possible to achieve the desired amplitude-frequency and correlationspectrum characteristics and reduce the dispersions of the oscillations of the modular power unit by a factor of 3-4. The rational rigidity of the elastic and dissipative link between the two modules in the ploughing process was observed at a resistance coefficient value of $1.65 \mathrm{kN} \cdot \mathrm{s} \cdot \mathrm{m}^{-1}$.
\end{abstract}

Keywords: modular power unit; optimal design; product modelling; smoothness of movement; vertical oscillation.

\section{Introduction}

The alternative development trend in the tractor engineering, which involves configuring energy intensive power units on the modular principle with the use of process modules [1], [2], [3], [4], [5], has not yet been given sufficiently much consideration. At the same time, the multiple-axle modular power unit designed in this way makes it possible to employ more fully the power reserve contained in the tractor engine via the traction wheels of the process module by means of using not only the tractor's weight but also the weight of the whole combined tractor-implement unit, including its process part, as the adhesive weight [6], [7], [8].

The completed tests with the prototype models of modular power units have shown [9], [10], that one of the advantages of using a process module is the possibility to damp its vertical oscillations generated by the irregularities on the agronomic background and the force of resistance of the agricultural implement.It is important because the continuous variation of the external load in the real conditions of the combined tractor-implement unit operation results in the 
reduction of the rated capacity of the power unit's engine and the increase of the specific fuel consumption per completed work unit. In the solution under consideration, the vertical oscillations of the modular power unit are damped not only by its cushioning system, but also by the inertia of the mass of the process module.

The research into the elastic damping properties of the process module is of certain interest, because they could provide for substantially reducing the dynamic load that acts on the transmission and engine of the power unit [11]. Hence, raising the efficiency of utilisation of combined tractor-implement units with modular combination layouts based on energy intensive tractors by means of improving the smoothness of their movement is an important scientific problem with major practical implications.

The history knows a number of attempts to engineer multiple-axle tractors in order to improve the adhesion to the bearing surface and reduce the level of the latter's compaction. In former times, for example, three-axle versions of combined tractor-implement units based on the blocks and assemblies of the T-150K and K-701 tractors were in general use [12]. Another known specimen was the tractor by Valmet with the wheel arrangement $6 \times 4$, in which the rear axle could be raised into the transport position by the hydraulic mechanism [13]. Once, the Fendt company showed its new concept design of a three-axle tractor Trisix Vario [14] featuring six identical tyres, which integrated the advantages of wheeled tractors and tracked ones. The Versatile company produced the Big Roy tractor with four cushioned driving axles [15]. The Deutz-Fahr company promoted the Agro XXL eight-wheel tractor [16]. Each two wheels on one side of it were connected with each other via the bogie type axle system and were both driven by the same central drive [17]. The rear section of the tractor featured the platform equipped with the system for quick coupling with containers of the Jost brand and the ball-and-socket hitch unit for attaching semi-trailers [18].

Although the implementation of multiple-axle energy intensive tractors improves the traction and adhesion characteristics, it does not provide for solving the problem of the full utilisation of the increased engine power output via the hitch linkage. In this context, a more efficient approach can be found in the modular concept of the power unit design used in the family of modular power units (MPU), including MPU-150, MPU-200 and MPU-300 [4], [5], [6], [9] (Fig. 1).
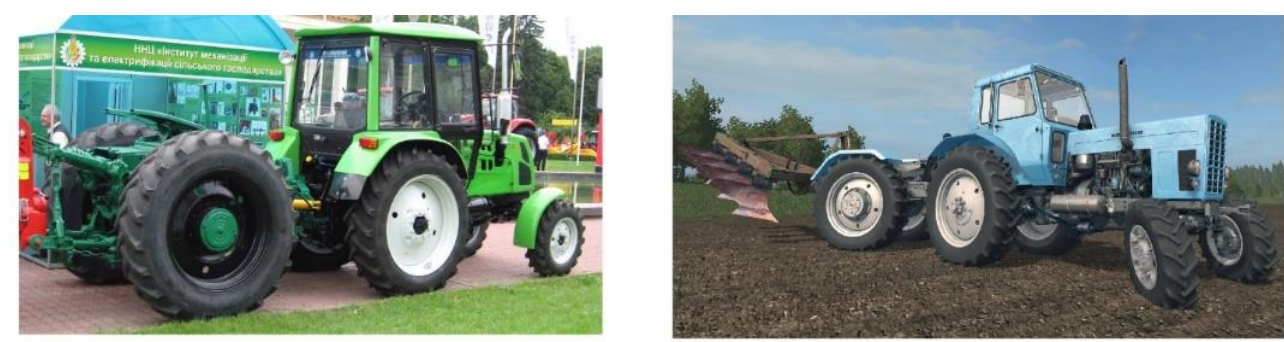

a)
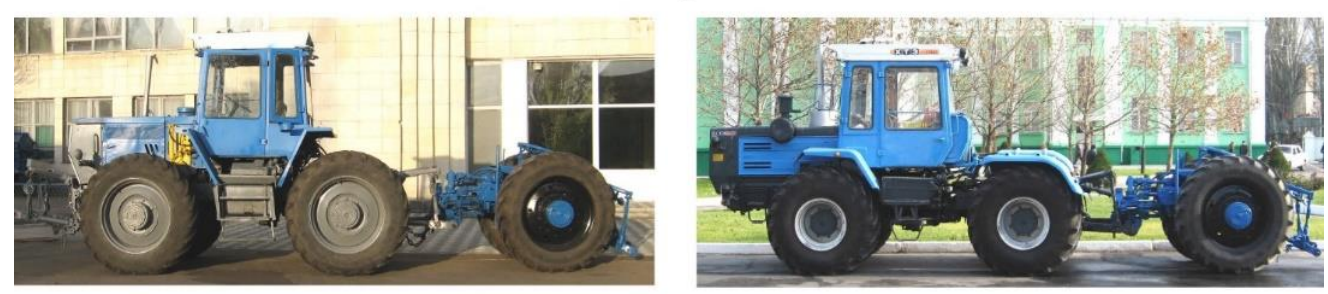

b)

Fig. 1. Modular power units: a) MPU-150 and MPU-200; b) MPU-300

The design layout of modular power units (Fig. 1) involves the connection (of the articulated frame type) of the tractor (power module) with the process module by means of the three-point suspension system that enables the angular mobility of the latter module in the vertical and horizontal planes. The prototype models of the known process modules are usually equipped with active wheels driven by the tractor engine, hydraulic suspension, fifth-wheel and drawbar hitch mechanisms, power take-off shaft and other devices required for performing the field and transport operations [19]. The primary purpose of the process module is the production of an additional traction effort using the excess power of the engine installed in the energy intensive tractor. The fundamental difference of modular power units from conventional tractors is their high versatility due to their variable traction force category, which enables either reducing the range of tractors in case their fleet is too manifold or, vice versa, solving the problem of absence of power units in some traction force categories. That is achieved by the appropriate selection of the process module weight, which provides for the transition of the modular power unit into the next traction force category [4], [5], [6], [9].

The research into the elastic damping properties of the process module is of certain interest, because it could provide for a substantial reduction of the dynamic load on the transmission and engine of the power module as well as improve the vibration protection of the driver-operator [6], [9].

The aim of the investigations completed by the authors was to improve the smoothness of movement of the modular power unit used as part of an agricultural combined unit by means of establishing an elastic damping connection between the power module and the process one. 


\section{Materials and Methods}

The synthesis of the parameters of the connection between the modules in the modular power unit was done by modelling the conditions of its operation in the PC. The formal characterization of the process under investigation was based on the principles of the theoretical mechanics, the theory of tractor, the statistical dynamics and the frequencydomain methods of the automatic control theory for linear dynamic systems responding to statistically random perturbing actions.

The experimental investigations were based on both the generally accepted standard methods and the specially developed original ones with the use of strain-gauge and vibrographical equipment, the detected signals being recorded in the PC with the use of an analogue-digital converter. The results of the experiments were processed in the PC with the use of the probability calculus and correlation-spectrum analysis. The subject of the experimental investigations was a ploughing combined unit including a modular power unit of a multi-purpose ploughing type, which comprised power and process modules and a PLN-5-35 strain-measuring plough (Fig. 2).

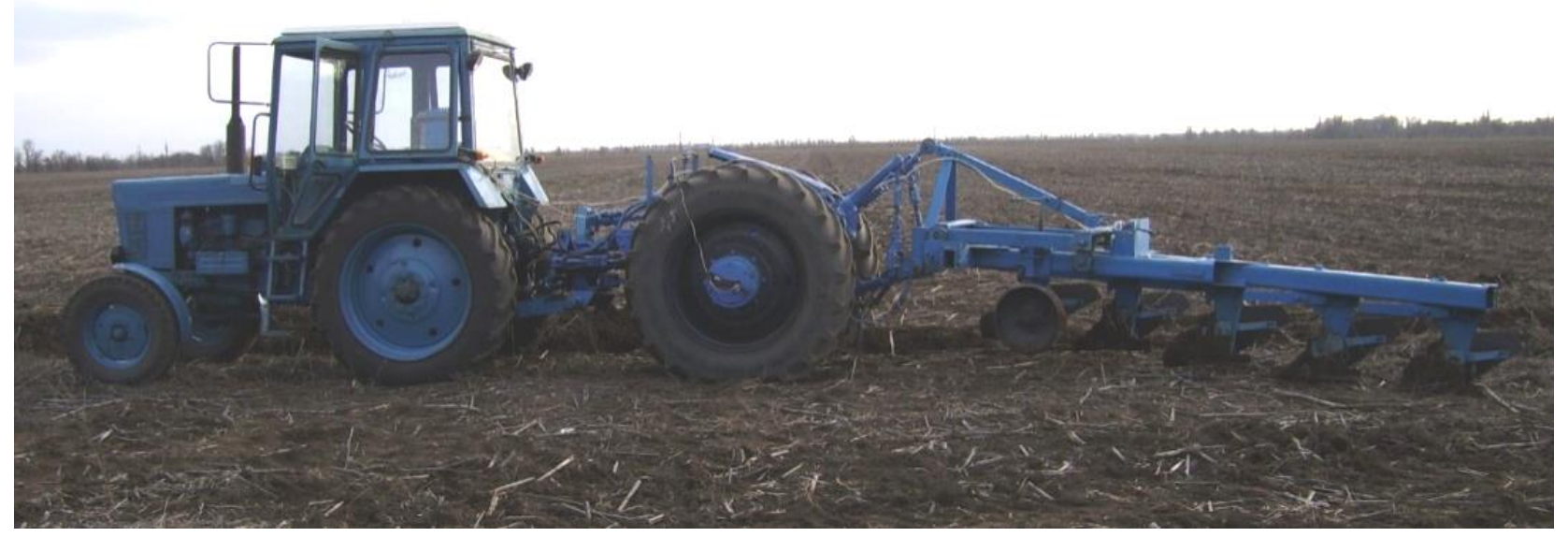

Fig. 2. Modular power unit as part of ploughing combined unit

The process module (Fig. 2) was a single-axle power driven hitching bogie designed as an articulated carriage frame equipped with power driven wheels. In its front section, the process module was equipped with a standard tractor device for mounting it on the hitch links of the power module's rear hitch linkage. In its rear section, the process module featured a hitch linkage unified with the hitch linkages of commercially produced tractors.

The field and laboratory experimental research into the operation of the modular power unit as part of a ploughing combined unit were carried out in the process of ploughing a sunflower stubble field. The average value of the soil moisture content in the $0 \ldots 15 \mathrm{~cm}$ layer was equal to $23.7 \%$, the density $-1.43 \mathrm{~g} \cdot \mathrm{cm}^{-3}$.

In order to pursue the theoretical research into the smoothness of movement of a modular power unit acting as part of a ploughing combined unit moving over the surface irregularities of the agronomic background, the equivalent schematic model of the combined unit is to be generated (Fig. 3) and the forces acting on the combined unit are to be represented in it. For the generation of the above-mentioned equivalent schematic model, it is appropriate and sufficient to give consideration to the oscillations of the flat figure that has a shape of the lateral projection of the ploughing combined unit based on a modular power unit solely in the vertical plane that contains the longitudinal symmetry section of the modules and plough (Fig. 3). In the said equivalent schematic model, the plough is represented by one equivalent plough bottom, in which the resistance centre of the plough is contained. The mechanical link between the power and process modules has to be supplemented with elastic and dissipative members. In Fig. 3, the said link is represented by the Hertz equivalent dynamic model, in which the elastic member is represented by a spring with a stiffness of $\tilde{N}_{h}$, the dissipative one - by a piston with a resistance coefficient of $K_{h}$.

During the operational motion of the ploughing combined unit, the jolts and impacts caused by the field profile irregularities and the variation of the tractive resistance offered by the agricultural implement are transferred to the power and process modules as well as the plough. In the general case, that results in the modules of the power unit performing interrelated translational vertical movements. The power module has two degrees of freedom: the vertical displacement $Z_{t}$ of the centre of mass located at the point $S_{t}$ and the angular oscillations $\varphi_{t}$ of the frame. The process module has only one degree of freedom - the vertical displacement $Z_{m}=Z_{3}$ of its centre of mass located at the point $S_{m}$. Hence, the vertical displacements $Z_{1}, Z_{2}$ and $Z_{3}$ of the modular power unit's axles are designated as the generalized coordinates. 


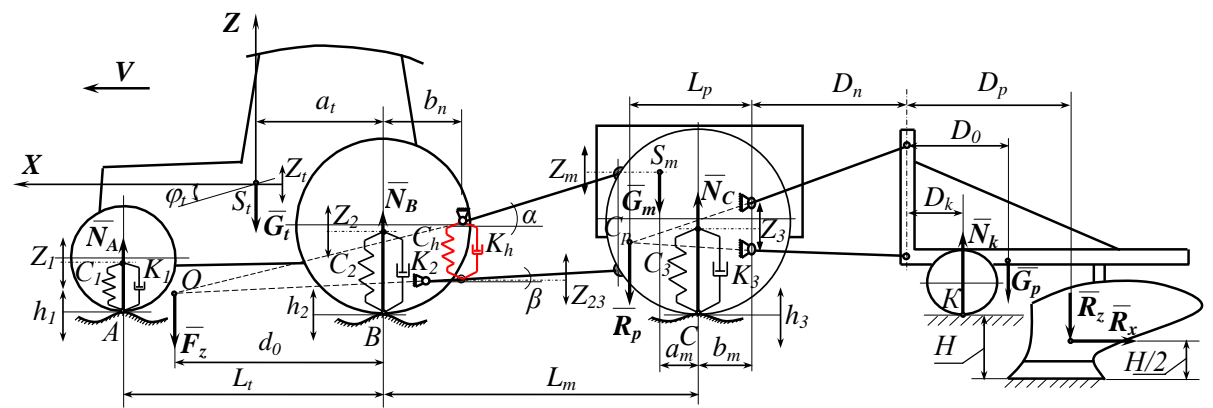

Fig. 3. Equivalent schematic model of motion of modular power unit as part of ploughing combined unit in longitudinal and vertical plane.

\section{Theory and Modelling}

For the purpose of generating a mathematical model for the motion of a modular power unit as part of a ploughing combined unit in the vertical plane, the following Lagrange equation of the second kind can be used:

$$
\frac{d}{d t}\left(\frac{\partial T_{t}}{\partial \dot{q}_{i}}\right)-\frac{\partial T_{t}}{\partial q_{i}}+\frac{\partial E_{t}}{\partial q_{i}}+\frac{\partial F_{t}}{\partial \dot{q}_{i}}=Q_{i}
$$

where $q_{i}, Q_{i}-i$ th generalized coordinate and force, respectively; $T_{t}, E_{t}$ - kinetic and potential energies of the power unit, respectively; $F_{t}$ - dissipative function. In view of the fact that the kinetic energy depends solely on the velocity of motion and is independent of the generalized coordinate:

$$
\frac{\partial T_{t}}{\partial q_{i}}=0
$$

In that case, the motion of the dynamic system under consideration in the vertical plane can be described with the use of the Lagrange equation of the second kind as follows:

$$
\frac{d}{d t}\left(\frac{\partial T_{t}}{\partial \dot{q}_{i}}\right)+\frac{\partial E_{t}}{\partial q_{i}}+\frac{\partial F_{t}}{\partial \dot{q}_{i}}=Q_{i}
$$

In the generation of the equation (3), the following facts and assumptions have been used: the motion of the ploughing combined unit is assumed to be steady and straight-line, while the profiles of the bearing surfaces under the wheels on the right and left sides of the modular power unit are assumed to be identical; during their travel on the field, the wheels of the power and process modules maintain continuous contact with the surface of the agronomic background, which is a random stationary ergodic function of the covered distance; the variation of the plough tractive resistance does not have any significant impact on the velocity of the combined unit's translational motion, therefore, the latter is assumed to be constant; the angular oscillations of the plough can be neglected; at the small angles $\varphi_{t}$ of displacement of the power module's frame the following equations are true: $\tan \varphi_{t} \approx \varphi_{t}, \cos \varphi_{t} \approx 1$. After finding the kinetic energy $T_{t}$ and the potential energy $E_{t}$ as well as the respective dissipative $F_{t}$ and generalized $Q_{i}$ forces, the mathematical model of the vertical oscillatory motions of the modular power unit as part of a ploughing combined unit is obtained in the form of the following system of differential equations:

$$
\begin{aligned}
& \grave{A}_{11} \cdot \ddot{Z}_{1}+\grave{A}_{12} \cdot \dot{Z}_{1}+\grave{A}_{13} \cdot Z_{1}+\grave{A}_{14} \cdot \ddot{Z}_{2}=f_{11} \cdot \dot{h}_{1}+f_{12} \cdot h_{1}+f_{13} \cdot R_{\tilde{o}}+f_{14} \\
& \grave{A}_{21} \cdot \ddot{Z}_{2}+\grave{A}_{22} \cdot \dot{Z}_{2}+\grave{A}_{23} \cdot Z_{2}+\grave{A}_{24} \cdot \ddot{Z}_{1}=f_{21} \cdot \dot{h}_{2}+f_{22} \cdot h_{2}+f_{23} \cdot R_{\tilde{o}}+f_{24} \text {, } \\
& \grave{A}_{31} \cdot \ddot{Z}_{3}+\grave{A}_{32} \cdot \dot{Z}_{3}+\grave{A}_{33} \cdot Z_{3}=f_{31} \cdot \dot{h}_{3}+f_{32} \cdot h_{3}+f_{33} \cdot R_{\tilde{o}}+f_{34} \text {, } \\
& \text { where } \grave{A}_{11}=\frac{M_{t} \cdot a_{t}^{2}+J_{t}}{L_{t}^{2}} \text {; } \\
& A_{12}=K_{1} ; A_{13}=C_{1} ; \\
& \grave{A}_{14}=\frac{2\left[M_{t} \cdot a_{t} \cdot\left(L_{t}-a_{t}\right)-J_{t}\right]}{L_{t}^{2}} ;
\end{aligned}
$$




$$
\begin{aligned}
& \grave{A}_{21}=\frac{M_{t} \cdot\left(L_{t}-a_{t}\right)^{2}-J_{t} ;}{L_{t}^{2}} ; \\
& \grave{A}_{22}=\hat{E}_{2} ; A_{23}=C_{2} ; \\
& \grave{A}_{24}=\frac{2\left[M_{t} \cdot a_{t} \cdot\left(L_{t}-a_{t}\right)-J_{t}\right]}{L_{t}^{2}} ; \\
& A_{31}=M_{m} ; \grave{A}_{32}=\hat{E}_{3} ; A_{33}=\tilde{N}_{\xi} ; \\
& f_{11}=K_{1} ; f_{12}=C_{1} ; \\
& f_{13}=\frac{d_{0} \cdot\left(L_{p}-b_{m}\right) \cdot\left[0.5 H-0.2\left(D_{p}-D_{k}\right)\right] ;}{L_{t} \cdot\left(L_{p}+D_{n}+D_{k}\right) \cdot\left(L_{m}+d_{0}\right)} \\
& f_{21}=K_{2} ; f_{22}=\tilde{N}_{2} ; \\
& f_{23}=\frac{\left(1-d_{0} \cdot L_{t}^{-1}\right) \cdot\left(L_{p}-b_{i}\right) \cdot\left[0.5 H-0.2\left(D_{p}-D_{k}\right)\right] ;}{\left(L_{p}+D_{n}+D_{k}\right) \cdot\left(L_{m}+d_{0}\right)} \cdot\left[G_{m} \cdot\left(a_{m}-f_{m} \cdot r_{k m}\right)-\frac{G_{p} \cdot\left(L_{p}-b_{m}\right) \cdot\left(D_{0}-D_{k}\right)}{\left(L_{p}+D_{n}+D_{k}\right)}\right] ; \\
& f_{24}=\frac{\left(1-d_{0} \cdot L_{t}^{-1}\right)}{\left(L_{m}+d_{0}\right)}\left[G_{m} \cdot\left(a_{m}-f_{m} \cdot r_{k m}\right)-\frac{G_{p} \cdot\left(L_{p}-b_{m}\right) \cdot\left(D_{0}-D_{k}\right)}{\left(L_{p}+D_{n}+D_{k}\right)}\right] ; \\
& f_{31}=K_{3} ; f_{32}=\tilde{N}_{3} ; \\
& f_{33}=\frac{\left[0.5 H-0.2\left(D_{p}-D_{k}\right)\right]}{\left(L_{p}+D_{n}+D_{k}\right)} \cdot\left[1-\frac{L_{p}-b_{m}}{L_{m}+d_{0}}\right] ; f_{34}=\frac{G_{p} \cdot\left(D_{0}-D_{k}\right)}{\left(L_{p}+D_{n}+D_{k}\right)} \cdot\left[\frac{L_{p}-b_{m}}{L_{m}+d_{0}}-1\right]-\frac{G_{m} \cdot\left(a_{m}-f_{m} \cdot r_{k m}\right)}{\left(L_{m}+d_{0}\right)} \cdot
\end{aligned}
$$

In the system of equations (4), the following parameters are denoted: $M_{t}, J_{t}$ - mass and moment of inertia in the longitudinal and vertical plane of the power module; $M_{m}, G_{m}$ - mass and gravity force of the process module; $G_{p}$ - gravity force of the plough; $f_{m}, r_{k m}$ - resistance coefficient and rolling radius of the wheels of the process module; $R_{x}$ - horizontal component of the plough tractive resistance; $K_{1}, K_{2}, K_{3}$ and $C_{1}, C_{2}, C_{3}$ - respectively, the reduced resistance coefficients of the dissipative and elastic members in the process of damping the oscillations of the modular power unit, which are described by the following expressions:

$$
\begin{aligned}
& \hat{E}_{1}=\frac{\hat{E}_{s 1} \cdot \hat{E}_{h} \cdot b_{n}^{2}}{\hat{E}_{h} \cdot b_{n}^{2}+2 \cdot \hat{E}_{s 1} \cdot L_{t}^{2}} ; \\
& \hat{E}_{2}=\frac{\hat{E}_{s 2} \cdot \hat{E}_{h} \cdot\left(L_{t}+b_{n}\right)^{2}}{\hat{E}_{h} \cdot\left(L_{t}+b_{n}\right)^{2}+2 \cdot \hat{E}_{s 2} \cdot L_{t}^{2}} ; \\
& \hat{E}_{3}=\frac{\hat{E}_{s 3} \cdot \hat{E}_{h} \cdot b_{n}^{2}}{\hat{E}_{h} \cdot b_{n}^{2}+2 \cdot \hat{E}_{s 3} \cdot\left(L_{m}-b_{n}\right)^{2}} ; \\
& \tilde{N}_{1}=\frac{\tilde{N}_{s 1} \cdot \tilde{N}_{h} \cdot b_{n}^{2}}{\tilde{N}_{h} \cdot b_{n}^{2}+2 \cdot \tilde{N}_{s 1} \cdot L_{t}^{2}} ; \\
& \tilde{N}_{2}=\frac{\tilde{N}_{s 2} \cdot \tilde{N}_{h} \cdot\left(L_{t}+b_{n}\right)^{2}}{\tilde{N}_{h} \cdot\left(L_{t}+b_{n}\right)^{2}+2 \cdot \tilde{N}_{s 2} \cdot L_{t}^{2}} ; \\
& \tilde{N}_{3}=\frac{\tilde{N}_{s 3} \cdot \tilde{N}_{h} \cdot b_{n}^{2}}{\tilde{N}_{h} \cdot b_{n}^{2}+2 \cdot \tilde{N}_{s 3} \cdot\left(L_{m}-b_{n}\right)^{2}},
\end{aligned}
$$

where $K_{s 1}, K_{s 2}, K_{s 3}$ and $C_{s 1}, C_{s 2}, C_{s 3}$ - respectively, the resistance coefficients of the dissipative and elastic members in the cushioning systems of the axles of the power and process modules. The nature of other design parameters is made obvious by Fig. 3. If the Laplace transformations are applied to the system of differential equations (4), the following mathematical model in operator notation is obtained for the dynamics of the motion performed in the longitudinal and vertical plane by the modular power unit as part of a ploughing combined unit: 


$$
\left.\begin{array}{l}
K_{11} \cdot Z_{1}(s)+K_{12} \cdot Z_{2}(s)+K_{13} \cdot Z_{3}(s)= \\
=F_{11} \cdot h_{1}(s)+F_{12} \cdot h_{2}(s)+F_{13} \cdot h_{3}(s)+F_{14} \cdot R_{x}(s)+F_{15}, \\
K_{21} \cdot Z_{1}(s)+K_{22} \cdot Z_{2}(s)+K_{23} \cdot Z_{3}(s)= \\
=F_{21} \cdot h_{1}(s)+F_{22} \cdot h_{2}(s)+F_{23} \cdot h_{3}(s)+F_{24} \cdot R_{x}(s)+F_{25}, \\
K_{31} \cdot Z_{1}(s)+K_{32} \cdot Z_{2}(s)+K_{33} \cdot Z_{3}(s)= \\
=F_{31} \cdot h_{1}(s)+F_{32} \cdot h_{2}(s)+F_{33} \cdot h_{3}(s)+F_{34} \cdot R_{x}(s)+F_{35},
\end{array}\right\}
$$

where $K_{11}=A_{11} \cdot s^{2}+A_{12} \cdot s+A_{13}$;

$$
\begin{aligned}
& K_{12}=A_{14} \cdot s^{2} ; \\
& K_{13}=K_{23}=K_{31}=K_{32}=0 ; \\
& K_{21}=A_{24} \cdot s^{2} ; \\
& K_{22}=A_{21} \cdot s^{2}+A_{22} \cdot s+A_{23} ; \\
& K_{33}=A_{31} \cdot s^{2}+A_{32} \cdot s+A_{33} ; \\
& F_{11}=f_{11} \cdot s+f_{12} ; \\
& F_{12}=F_{13}=F_{21}=F_{23}=F_{31}=F_{32}=0 ; \\
& F_{14}=f_{13} ; F_{15}=f_{14} ; \\
& F_{22}=f_{21} \cdot s+f_{22} ; \\
& F_{24}=f_{23} ; F_{25}=f_{24} ; \\
& F_{33}=f_{31} \cdot s+f_{32} ; F_{34}=f_{33} ; F_{35}=f_{44} ; \\
& s=\frac{d}{d t}-\text { operator of differentiation. }
\end{aligned}
$$

In the system of equations (5), the heights of soil surface irregularities under the front $\left(h_{1}\right)$ and rear $\left(h_{2}\right)$ wheels of the power module and the wheels of the process module $\left(h_{3}\right)$ as well as the plough tractive resistance $\left(R_{x}\right)$ act as the input values. The initial parameters comprise the amplitudes of displacements, that is, the oscillations of the front $\left(Z_{1}\right)$ and rear $\left(Z_{2}\right)$ axles of the power module and the oscillations of the process module's frame $\left(Z_{3}\right)$.

In case of dynamic systems, the principal operators are transfer functions and frequency-response characteristics. Therefore, the impact that the values of the resistance coefficients of the dissipative and elastic link between the two modules have on the behaviour of the vertical oscillations of the ploughing combined unit has to be estimated with the use of the amplitude-frequency characteristics of the displacements and accelerations observed in the response of the dynamic system to the agronomic background profile irregularities and the variation of the plough tractive resistance.

The solving of the system of equations (5) in the operator form provides for obtaining the transfer functions and subsequently the frequency-response characteristics of the displacements $\grave{A}_{\mathrm{z}_{2} / h_{2}}(\omega)$ and $\grave{A}_{\mathrm{z}_{2} / R_{x}}(\omega)$ as well as the accelerations $\grave{A}_{\grave{2}_{2} / h_{2}}(\omega)$ at $s=i \cdot \omega$ (where $i$-imaginary unit, $\omega$ - frequency of the perturbing action).

In the experimental investigations, the dissipative resistance coefficient of the link between the two modules was designated as the variable factor. Its variation was instrumented by throttling the flow passage of the hydraulic pressure supply line to the main hydraulic cylinder in the hydraulic system of the power module's rear hitch linkage.

\section{Results and discussion}

The analysis of the amplitude-frequency characteristics of the vertical displacements of the power module's rear axle responding to the track profile oscillations has shown (Fig. 4) that bulk of the vertical oscillation spectrum is concentrated within the frequency range of $\omega=0-16 \mathrm{~s}^{-1}$. With regard to the desired response of the dynamic system to the agronomic background profile irregularities, raising the stiffness of the viscoelastic link between the two modules in the ploughing combined unit is an efficient measure, because it brings the amplitude-frequency characteristics close to zero.

As the value of the resistance coefficient $K_{h}$ of the dissipative link between the two modules rises from 0 to $1.80 \mathrm{kN} \cdot \mathrm{s} \cdot \mathrm{m}^{-1}$, the amplitudes of the oscillations performed by the rear axle of the power module are reduced almost by 
factor of 10, while the resonance peaks of the frequency-response characteristics are shifted into the low frequency range from $16.5 \mathrm{~s}^{-1}$ to $6.0 \mathrm{~s}^{-1}$, their maximum values simultaneously decreasing almost by factor of 4 (see Fig. 4). That is a positive case with regard to raising the smoothness of movement of the modular power unit, since such a follow (slave) system tends to copy the agronomic background irregularities without amplification.

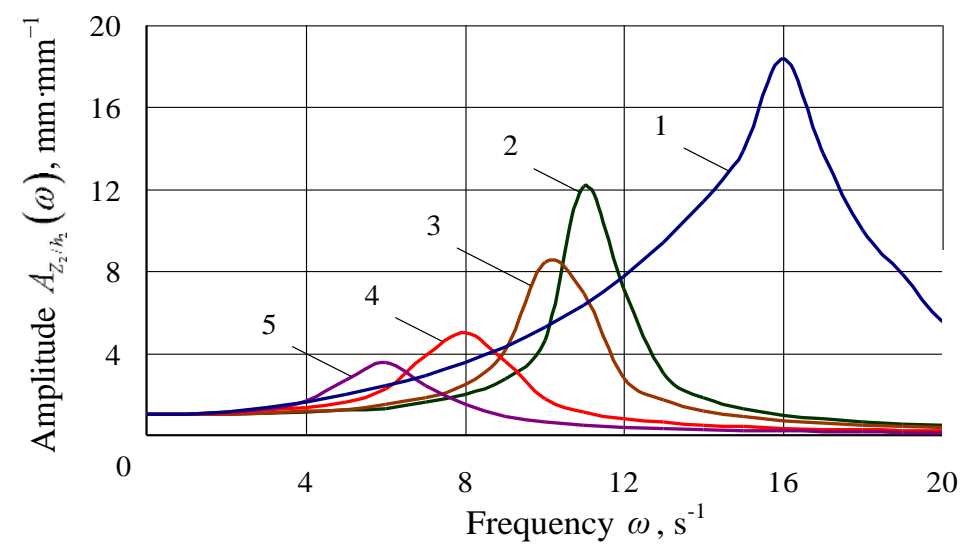

Fig. 4. Amplitude-frequency characteristics of vertical displacements of power module's rear axle in its response to track profile oscillations at different values of resistance coefficient of dissipative link between two modules:

1) $K_{h}=0 \mathrm{kN} \cdot \mathrm{s} \cdot \mathrm{m}^{-1}$; 2) $K_{h}=1.00 \mathrm{kN} \cdot \mathrm{s} \cdot \mathrm{m}^{-1}$; 3) $K_{h}=1.35 \mathrm{kN} \cdot \mathrm{s} \cdot \mathrm{m}^{-1}$; 4) $K_{h}=1.65 \mathrm{kN} \cdot \mathrm{s} \cdot \mathrm{m}^{-1} ; 5-K_{h}=1.80 \mathrm{kN} \cdot \mathrm{s} \cdot \mathrm{m}^{-1}$.

The analysis of the amplitude-frequency characteristics of the vertical oscillations of the power module's rear axle responding to the perturbations caused by the variation of the plough tractive resistance has shown (Fig. 5) that the oscillations of this perturbing factor have a significantly smaller effect on the smoothness of movement of the power unit, as compared to the effect of the oscillations of the longitudinal profile of the track. The maximum value of the oscillation amplitude decreases simultaneously with the increase of the resistance coefficient $K_{h}$ of the dissipative link between the two modules. At the same time, their maximums shift into the area of lower frequencies, which is also a desirable trend.

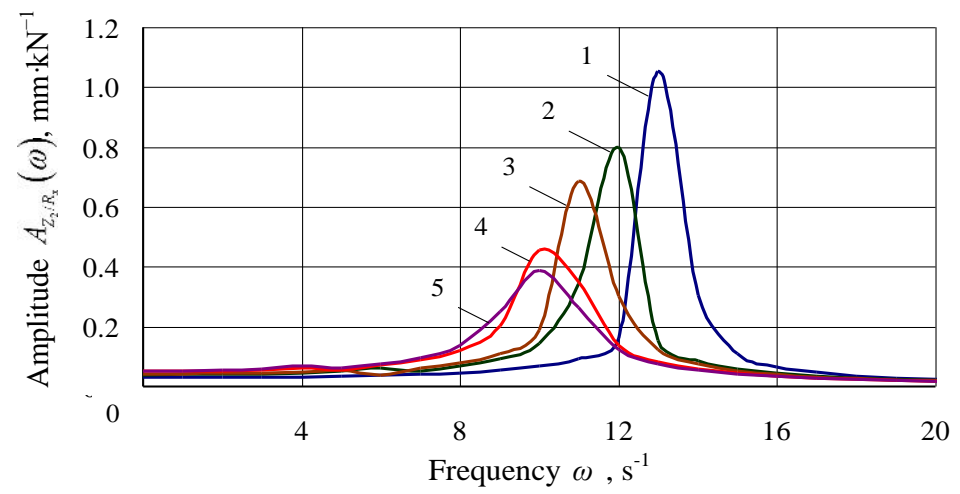

Fig. 5. Amplitude-frequency characteristics of vertical displacements of power module's rear axle in its response to plough tractive resistance variation at different values of resistance coefficient of dissipative link between two modules:

1) $K_{h}=0 \mathrm{kN} \cdot \mathrm{s} \cdot \mathrm{m}^{-1}$; 2) $K_{h}=1.00 \mathrm{kN} \cdot \mathrm{s} \cdot \mathrm{m}^{-1}$; 3) $K_{h}=1.35 \mathrm{kN} \cdot \mathrm{s} \cdot \mathrm{m}^{-1}$; 4) $K_{h}=1.65 \mathrm{kN} \cdot \mathrm{s} \cdot \mathrm{m}^{-1}$; 5$) K_{h}=1.80 \mathrm{kN} \cdot \mathrm{s} \cdot \mathrm{m}^{-1}$

The spread of the root-mean-square deviation of the plough tractive resistance in the conditions of the field and laboratory experimental research into the smoothness of movement of a modular power unit as part of a ploughing combined unit has been equal to $\pm(2.2 \ldots 3.9) \mathrm{kN}$. Hence, even at a resonance frequency of $13 \mathrm{~s}^{-1}$ (see Fig. 5), the rootmean-square deviation of the vertical oscillations of the power module's rear axle caused by the random nature of the variation of the implement tractive resistance is expected to be at a level of just $\pm(3 \ldots .5) \mathrm{mm}$.

As a result of the completed theoretical research into the vertical oscillations of the modular power unit acting as part of a ploughing combined unit, it has been established that the increase of the stiffness of the elastic and dissipative link between the process and power modules results in the frequency-response characteristics shifting into the area of lower frequencies with the simultaneous reduction of their maximum values. The pattern of the changes in the frequencyresponse characteristics of the combined unit responding to external perturbing actions caused by changes in the resistance coefficient of the dissipative link between the two modules is not uniform. The decrease of the size of the amplitude-frequency characteristic remains intensive, as $K_{h}$ rises up to $1.65 \mathrm{kN} \cdot \mathrm{s} \cdot \mathrm{m}^{-1}$. After that, it slows down. Thus, the obtained value of $K_{h}$ represents the rational level of stiffness for the elastic and dissipative link between the two modules. 
The results of the experimental investigations have proved that, when the ploughing combined unit moves at a velocity of $1.5 \ldots 1.7 \mathrm{~m} \cdot \mathrm{s}^{-1}$, main part of the dispersion of the accelerations during the vertical oscillations of the power module's rear axle is concentrated within the range of frequencies of $0 \ldots 16.0 \mathrm{~s}^{-1}$, the same as in case of the oscillations of the agronomic background's longitudinal profile.

The graphs of the normalized correlation functions of the vertical oscillations performed by a modular power unit operating as part of a ploughing combined unit represent functions, which contain, beside random components, also harmonic damped periodic oscillations (Fig. 6). The same nature of the oscillations is observed also in case of the agronomic background profile irregularities. The greatest length of correlation (increase of which is desirable) is achieved at the maximum possible stiffness of the elastic dissipative link between the two modules and is equal to approximately $0.62 \mathrm{~s}$. At the above-mentioned velocity of the ploughing combined unit, that corresponds to a length of $0.8 \ldots 0.9 \mathrm{~m}$.

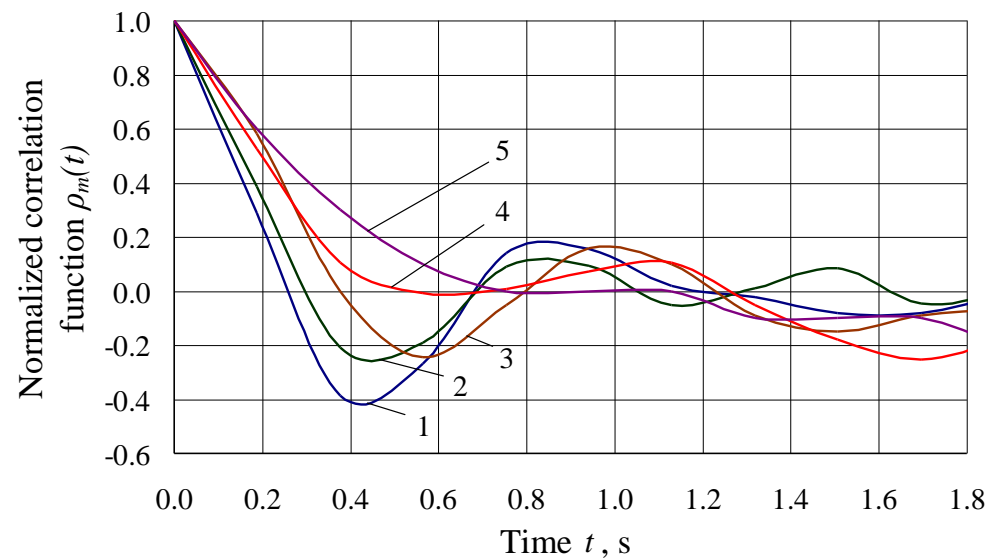

Fig. 6. Normalized correlation functions of accelerations during vertical oscillations of power module's rear axle at different values of resistance coefficient of dissipative link between two modules:

1) $K_{h}=0 \mathrm{kN} \cdot \mathrm{s} \cdot \mathrm{m}^{-1}$; 2) $K_{h}=1.00 \mathrm{kN} \cdot \mathrm{s} \cdot \mathrm{m}^{-1}$; 3) $K_{h}=1.35 \mathrm{kN} \cdot \mathrm{s} \cdot \mathrm{m}^{-1}$; 4) $K_{h}=1.65 \mathrm{kN} \cdot \mathrm{s} \cdot \mathrm{m}^{-1}$; 5) $K_{h}=1.80 \mathrm{kN} \cdot \mathrm{s} \cdot \mathrm{m}^{-1}$.

The assessment of the dynamics of the vertical oscillations of the modular power unit operated as part of the ploughing combined unit has supported the theoretical studies. It has been verified that the absence of an elastic dissipative link between the two modules $\left(K_{h}=0 \mathrm{kN} \cdot \mathrm{s} \cdot \mathrm{m}^{-1}\right)$ gives rise to a very negative oscillation process in the longitudinal and vertical plane with undesired characteristics and spectral density values as well as a greater dispersion (Fig. 7). At the same time, increasing the value of the resistance coefficient of the dissipative link between the two modules to $K_{h}=1.80 \mathrm{kN} \cdot \mathrm{s} \cdot \mathrm{m}^{-1}$ shrinks the frequency range of the main spectrum of the vertical oscillation acceleration dispersions to $8 \mathrm{~s}^{-1}$. And that is even shorter than the frequency range of the agronomic background profile oscillations, which is, again, a desirable situation.

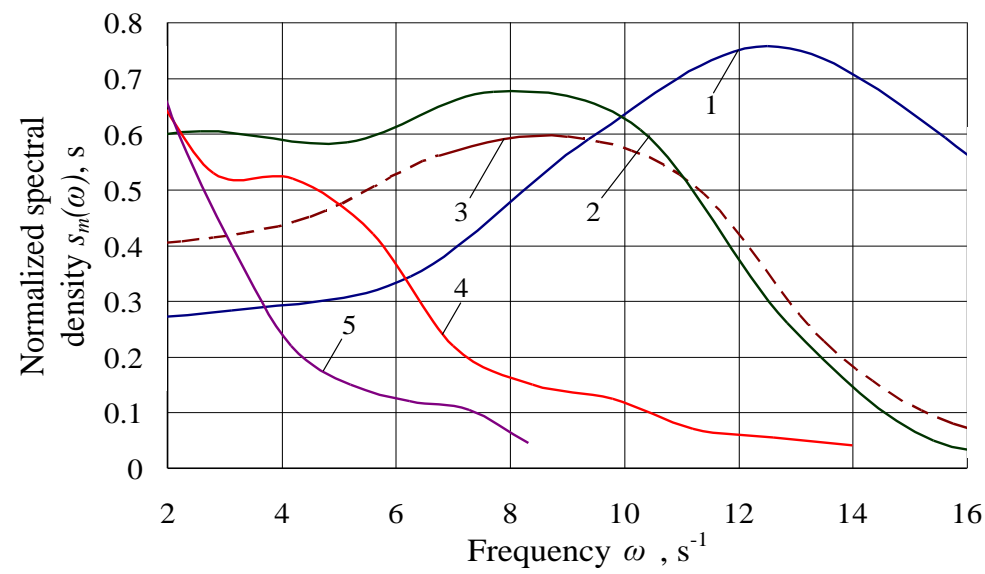

Fig. 7. Normalized spectral densities of accelerations during vertical oscillations of power module's rear axle at different values of resistance coefficient of dissipative link between two modules:

1) $K_{h}=0 \mathrm{kN} \cdot \mathrm{s} \cdot \mathrm{m}^{-1}$; 2) $K_{h}=1.00 \mathrm{kN} \cdot \mathrm{s} \cdot \mathrm{m}^{-1}$; 3) $K_{h}=1.35 \mathrm{kN} \cdot \mathrm{s} \cdot \mathrm{m}^{-1}$; 4) $K_{h}=1.65 \mathrm{kN} \cdot \mathrm{s} \cdot \mathrm{m}^{-1}$; 5) $K_{h}=1.80 \mathrm{kN} \cdot \mathrm{s} \cdot \mathrm{m}^{-1}$.

The pattern observed in the reduction of the dispersion of the accelerations during the vertical oscillations of the modular power unit as a result of the increase of the stiffness of the elastic and dissipative link between its modules is not uniform. The intensive decrease of the dispersion is observed, while $K_{h}$ rises up to a value of $1.65 \mathrm{kN} \cdot \mathrm{s} \cdot \mathrm{m}^{-1}$. After that, it remains roughly constant. In this case, the reduction of the dispersion of the vertical oscillation accelerations of the modular power unit by a factor of 3 is not accidental, because, according to the F-ratio test (Fisher's ratio test), at a significance level of 0.05 the null hypothesis of the equality of these statistical estimates is rejected. 
The comparison of the theoretically and experimentally obtained amplitude-frequency characteristics of the vertical oscillation accelerations of the power module's rear axle in the presence of an elastic and dissipative link between the two modules has proved (Fig. 8) that the processes in both cases feature approximately the same interval of variation of the frequency range.

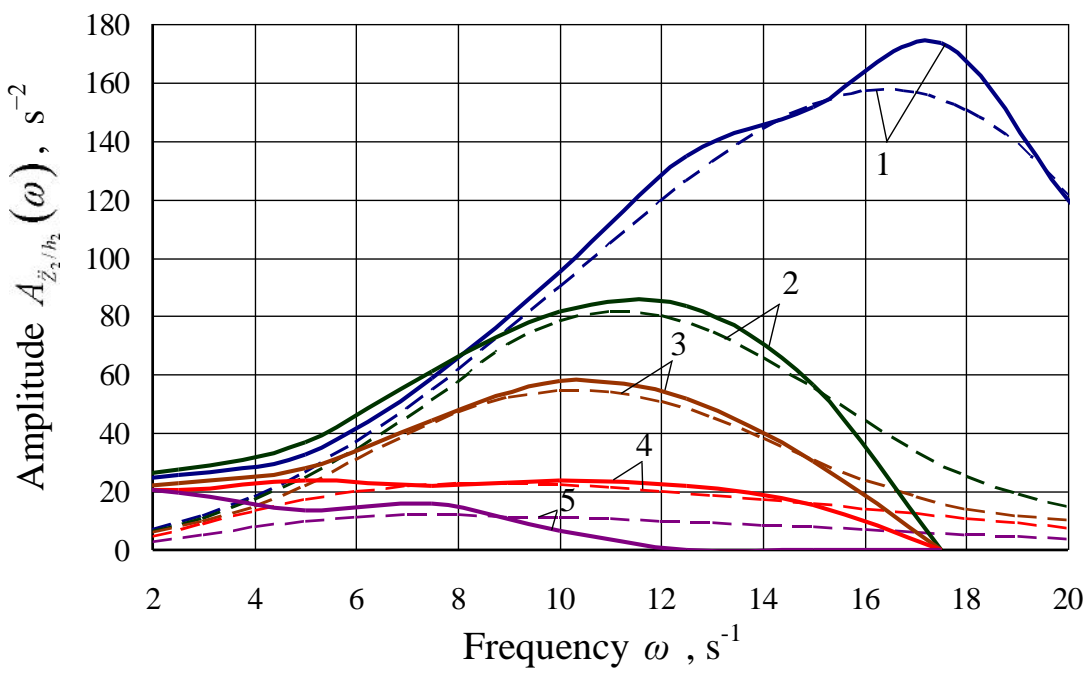

Fig. 8. Theoretical and experimental amplitude-frequency characteristics of vertical oscillation accelerations of power module's rear axle at different values of resistance coefficient of dissipative link between two modules:

1) $K_{h}=0 \mathrm{kN} \cdot \mathrm{s} \cdot \mathrm{m}^{-1}$; 2) $K_{h}=1.00 \mathrm{kN} \cdot \mathrm{s} \cdot \mathrm{m}^{-1}$; 3) $K_{h}=1.35 \mathrm{kN} \cdot \mathrm{s} \cdot \mathrm{m}^{-1}$; 4) $K_{h}=1.65 \mathrm{kN} \cdot \mathrm{s} \cdot \mathrm{m}^{-1}$; 5) $K_{h}=1.80 \mathrm{kN} \cdot \mathrm{s} \cdot \mathrm{m}^{-1}$.

Within the operation range of frequencies of $2 \ldots 16 \mathrm{~s}^{-1}$, the behaviour of the vertical oscillation accelerations of the modular power unit is close to the theoretical one, the difference not exceeding $8 \ldots 15 \%$, which is acceptable for practical purposes. According to the F-ratio test, at a statistical significance level of 0.05 the null hypothesis of the equality of the compared dispersions is not rejected within the whole range of variation of the value of the resistance coefficient of the dissipative link between the two modules.

The major part of the spectrum of dispersions of the plough tractive resistance variation is concentrated within the frequency range of $0 \ldots 18 \mathrm{~s}^{-1}$. Raising the stiffness of the link between the two modules has virtually no effect on the pattern of the implement tractive resistance variation. The non-uniformity of the plough oscillations has almost 10 times smaller effect on the smoothness of movement of the combined unit, than the perturbing actions generated by the irregularities of the longitudinal profile of the track.

The results of the operation and process testing of the modular power unit acting as part of the ploughing combined unit have made it obvious that the introduction of an elastic dissipative link between its two modules with a resistance coefficient of $1.65 \mathrm{kN} \cdot \mathrm{s} \cdot \mathrm{m}^{-1}$ enables increasing its velocity by $6 \%$. As a consequence of that, the productive capacity per hour of the main time of operation of the ploughing combined unit grows in direct proportion by the same 6\%. Apart from the growth of the output rate during the operation of the combined unit, its specific fuel consumption rate (per hectare) is reduced on the average by $12.4 \%$.

The assessment of the ploughing quality indices delivered by the combined unit under investigation has testified that the differences between the mean values of the surface ridgeness and the soil tilling depth as well as between the dispersions of the aforesaid indices are of random nature with a confidence level of $95 \%$.

\section{Conclusion}

1. The obtained adequate dynamic model of a modular power unit operating as part of an agricultural combined unit, which can be considered as components of a single dynamic system, provides for the research into its motion in the longitudinal and vertical plane. It has been established that increasing the resistance coefficient of the dissipative link between the two modules to a level of $1.80 \mathrm{kN} \cdot \mathrm{s} \cdot \mathrm{m}^{-1}$ results in the reduction of the amplitude of oscillations of the power module's rear axle by a factor of 10 , while the resonance peaks of the frequency-response characteristics shift into the lower frequency range from $16.5 \mathrm{~s}^{-1}$ to $6.0 \mathrm{~s}^{-1}$ and simultaneously their maximum values become reduced by a factor of 4. At the same time, the peaks of the amplitude-frequency characteristics of the modular power unit responding to the variation of the plough tractive resistance shift from $13.0 \mathrm{~s}^{-1}$ to $10.0 \mathrm{~s}^{-1}$ and simultaneously their maximum values decrease by a factor of 3 . The rational rigidity of the elastic and dissipative link between the two modules is found to be at a resistance coefficient value of $1.65 \mathrm{kN} \cdot \mathrm{s} \cdot \mathrm{m}^{-1}$. The further decrease of the amplitudes of its vertical oscillations is insignificant.

2. It has been established that the variation of the tractive resistance furnished by the agricultural implements has a 10 times smaller effect on the smoothness of movement of the modular power unit acting as part of a ploughing combined unit, as compared to the effect of the oscillations of the longitudinal profile of the track. 
3. On the basis of the experimental investigations, it has been established that the desirable behaviour of the normalized correlation functions and the spectral response characteristics of the vertical oscillations performed by the modular power unit used as part of a ploughing combined unit is observed, when the resistance coefficient of the elastic and dissipative link between the two modules is increased to a level of $1.65 \mathrm{kN} \cdot \mathrm{s} \cdot \mathrm{m}^{-1}$. In this case, the dispersion of the accelerations in the vertical oscillations of the modular power unit is reduced by a factor of 3 .

4. The operation and process testing has proved that the improvement of the smoothness of movement of the modular power unit working as part of an agricultural combined unit provides for the growth of its performance by $6 \%$ and the reduction of the power consumption by $12.4 \%$.

5. The operation of a modular power unit, in which the modules are connected with an elastic and dissipative link, as part of a ploughing combined unit does not impair the quality of tillage. It is possible to state with a confidence level of $95 \%$ that the differences between the mean values as well as the dispersions of the ploughing quality indices are of purely random nature.

6. Future research plans are aimed at optimisation of the vertical load of the wheels of the modular power unit, improvement in the pulling characteristics of the modular power unit and decrease in the influence of soil treading.

\section{References}

[1] Kutzbach H.D. (2000). Trends in Power and Machinery. Journal of Agricultural Engineering Research, Vol. 76 , No. 3, pp. 237-247, ISSN 0021-8634. DOI: 10.1006/jaer.2000.0574, available online at http://www.idealibrary.com.

[2] Steindorff, K.; Flecczoreck, T.; Kattenstroth, R.; Schattenberg, J.; Jünemann, D.; Robert, M.; Wulfmeier, K. (2010). Trends in agricultural machines and tractors: Observations on the occasion of the Agritechnica in Hannover. Olhydraulik und Pneumatik, Vol. 54, pp. 57-63.

[3] Simikič, M.; Dedovič, N.; Savin, L.; Tomič, M.; Ponjičan, O. (2014). Power delivery efficiency of a wheeled traktor at oblique drawbar force. Soil and Tillage Research, Vol. 141, pp. 32-43.

[4] Nadykto V. (2010). Modular energy units. The Ukrainian Farmer. Vol. 7, pp. 70-71. (In Ukrainian).

[5] Nadykto, V. (2020). The role of modular power units in the formation of the type of tractors in Ukraine. Tractors and agricultural machinery. Vol. 6, pp. 22-25. (In Russian).

[6] Bulgakov, V.; Kyurchev, V.; Nadykto, V.; Olt, J. (2015). Structure development and results of testing a novel modular power unit. Agriculture and Agricultural Science Procedia, ISSN 2210-7843, Vol. 7, pp. 40-44, DOI: 10.1016/j.aaspro.2015.12.028.

[7] Bulgakov, V.; Melnik, V.; Kuvachov, V., Olt, J. (2018). Theoretical study on linkage unit of wide span tractor, Proceedings of the 29th DAAAM International Symposium, pp.0180-0189, B. Katalinic (Ed.), Published by DAAAM International, ISBN 978-3-902734-20-4, ISSN 1726-9679, Vienna, Austria, DOI: 10.2507/29th.daaam.proceedings.026.

[8] Bulgakov, V., Nadykto, V., Kyurchev, S., Nesvidomin, V., Ivanovs, S., Olt, J. (2019). Theoretical background for increasing grip properties of wheeled tractors based on their rational ballasting. Journal of Agricultural Science XXX, p-ISSN 1024-0845, e-ISSN 2228-1893, Vol. 30, No. 2, pp. 78-84. DOI: 10.15159/jas.19.07

[9] Nadykto, V.; Kyurchev V.; Kuvachov, V. (2008). Recommendations for increasing the smooth movement of machine-tractor units based on modular energy means. Journal TSATU. Vol. 8, No. 8, pp. 16-21. (In Ukrainian).

[10] Sidorov, M. (2014). Elastic-damping properties of the transport and technological module as part of an agricultural machine-tractor unit. International Research Journal. Vol. 41, No. 10-2, pp. 119-121. (In Russian).

[11] Bulgakov, V.; Adamchuk, V.; Kuvachov, V.; Arak, M.; Olt, J. (2017). Study into movement of wide span tractors (vehicles) used in controlled traffic farming. Proceedings of the 28th DAAAM International Symposium: 28th DAAAM International Symposium on Intelligent Manufacturing and Automation, 08 - 11th November 2017, Zadar, Croatia, EU. ISSN 1726-9679, ISBN978-3-902734-11-2, Katalinic, B. (Ed.), pp. 0199-0208. Vienna, Austria: DAAAM International Vienna, DOI: 10.2507/28th.daaam.proceedings.027.

[12] Sudin J.; Gritsik B. (1989). Self-propelled machines for chemicalization. Tractors and agricultural machinery. Vol. 7 pp. 40-42. (In Russian).

[13] Andreev, A.F.; Kabanau, V.I.; Vantsevich, V.V. (2010). Driveline Systems of Ground Vehicles. Theory and Design. CRC Press, Taylor \& Francis Group, ISBN 978-1-4398-1728-5, 758 p.

[14] https://www.tractordata.com/news/2007/11/agco-introduced-fendt-trisix-vario-tractor.html. AGCO Press Relase November12, 2007. AGCO introduces Fendt TRISIX tractor at Agritechnica. 2007Accessed on: 2020-04-23.

[15] https://www.rbauction.qc.ca/blog/five-of-the-world-s-biggest-tractors. Five of the World's Biggest Tractors, Septembre 19, 2013. Accessed on: 2020-04-23.

[16] http://www.deutz-traktoren.de/traktoren/agro_xxl/info.php. Deutz-Fahr Agro XXL. Accessed on: 2020-04-23.

[17] https://www.wochenblatt.com/landwirtschaft/nachrichten/agritechnica-acht-raeder-und-600-ps-8825705.html. Agritechnica: Acht Räder und 600 PS. Wochenblatt, 09.11.2009. Accessed on: 2020-04-23.

[18] 600 h.p. on 8 wheels. Modern agricultural machinery and equipment. 2010, No. 1, pp. 20-22. (In Russian).

[19] Kuvachov, V.; Katyukha, D. (2009). Trends in the development of robust ownership of block-modular units. Journal TSATU. Vol. 9, No. 3, pp. 82-86. (In Ukrainian). 